\title{
Evaluation of Rat Plasma Proteins after Bothropic Venom Inoculation and Treatment with Mesenquimal Stem Cells
}

\author{
Thalita Costa Telles ${ }^{1}$, Ana Flávia Ribeiro Machado Michel ${ }^{1}$, Maria Lúcia ${ }^{2}$, Bruno Martins \\ Melo $^{3}$, Adriane Costa-Val Pimenta Bicalho ${ }^{1}$, Natália Melo Ocarino ${ }^{1}$ and Marilia Martins \\ Melo $^{1 *}$ \\ ${ }^{1}$ Departamento de Clínica e Cirurgia Veterinárias; Escola de Veterinária; Universidade Federal de Minas Gerais; \\ Belo Horizonte - MG - Brasil. ${ }^{2}$ Departamento de Biologia; Universidade José do Rosário Vellano; Alfenas - MG - \\ Brasil. ${ }^{3}$ Departamento de Pediatria; Faculdade de Medicina; Universidade Federal de Minas Gerais; Belo \\ Horizonte - MG - Brasil
}

\begin{abstract}
The aim of this work was to evaluate the mesenchymal stem cells treatment of rats with myonecrosis caused by Rhinocerophis alternatus venom through acute phase proteins $(A P P)$ profile. The animals were distributed into three experimental groups (G1, G2 and G3). G1 and G2 were inoculated with $120 \mu \mathrm{g}$ of R. alternatus venom diluted in $200 \mu L$ of ultra-pure water in gastrocnemic muscle, while G3 received $200 \mu L$ of ultra-pure water. Three days after, G1 was treated with $5 \times 10^{6}$ MSC diluted in PBS and G2 and G3 only with PBS. Each three days after the treatments $\left(3^{\text {rd }}, 6^{\text {th }}, 9^{\text {th }}, 12^{\text {th }} 15^{\text {th }}\right.$ days), blood of five animals in each group was collected in order to evaluate the APP. A decrease $(P<0.05)$ in $\alpha 2$-globulin fraction was observed in $G 1$ on the $6^{\text {th }}$ day. In G1 and G2, a raise $(P<0.05)$ was observed in $\beta$ globulin, a common occurrence in the late phases of inflammatory process, although no significant difference was observed between them. Concerning gamma globulins levels, on the $6^{\text {th }}$ day after the treatments, in G1 and G2 groups, increase in the levels was observed. These data showed that the MSC treatment after bothropic envenomation in the rats caused alteration in APP.
\end{abstract}

Key words: Rhinocerophis alternatus venom, Rats, Mesenquimal stem cell, Inflammatory proteins

\section{INTRODUCTION}

The majority of snake bite accidents in South America are inflicted by the species belonging to Bothrops genus (Bochner and Struchiner 2003). The bothropic venom induces a qualitatively similar pathophysiological picture, characterized by immediate and prominent local tissue damage (edema, hemorrhage and mionecrosis), vascular alterations (hemorrhage and hypovolemic shock) and coagulation disorders (defibrination) (Chiacchio et al. 2011).
If specific antivenom (antibothropic) administration is initiated rapidly after envenomation, neutralization of systemic effects is usually successfully achieved, but neutralization of the local tissue damage is a more difficult task. This therapy has low and limited effectiveness against the local myonecrosis and cytotoxicity (Gutiérrez and Ownby 2003; Quesada et al. 2006; Silva et al. 2007). In a number of snake bite cases, lack of neutralization of local effects results in permanent sequelae, with tissue loss (Battellino et al. 2003).

\footnotetext{
*Author for correspondence: mariliamm@ufmg.br
} 
Due to the relevance of local effects in envenomation induced by the snakes of the genus Bothrops, several studies have been made on its different perspectives (Dourado et al. 2008). The use of phytotherapy against the snake venom has long been recognized, even in modern times but only for the last 20 years, it gained closer scientific attention (Mors et al. 2000). However, the isolation of plant compounds is difficult and expensive and often only a little amount can be isolated.

The mesenchymal stem cell (MS) therapy has been a promise for the repair of acute and chronic cutaneous wounds. MSC has the unusual capacity for self-renewal and differentiation, which has a high therapeutic value in reprogramming growth of tissues to repair injuries and treat diseases (Alonso and Fuchs 2003).

Another important property of MSC is to generate the cell types of tissues completely different from its origin, a phenomenon called plasticity (Gomillion and Burg 2006; Fuchs 2008). Recent studies have shown that MSC from the bone marrow can differentiate into various cells such as ectodermal, mesodermal and endodermal when transplanted into the body, repairing surgically induced wounds and burn injuries (Liu et al. 2008). Thus, through what is known by the regenerative medicine and cell therapy, it can be inferred that MSC can be used to repair the damaged tissue or wounds, which has minimized the complications caused by skin graft rejection of patients suffering from extensive burns or skin lesions (Metcalfe and Ferguson 2007; Liu et al. 2008).

The use of the MSC as treatment for the injuries caused by snake venom has not been reported in the literature. Considering the severity of local lesions observed in bothropic envenomation and the difficulty to reverse these manifestations, the search for novel toxin inhibitors represents a potential promise for improving the treatment of this serious aspect of this envenomation. In the present work, the ability of MSC to antagonize the myonecrosis in rats after venom injection was studied, evaluating some of the early inflammatory changes, such as acute phase proteins (APP).

\section{MATERIAL AND METHODS}

\section{Cell Harvesting and Culture}

To obtain bone marrow samples, three female rats (30 days old) were sacrificed with an overdose of anesthesia (pentobarbital sodium, $30 \mathrm{mg} / \mathrm{kg}$ ). The femurs and tibias were removed from the attached muscle and connective tissue under aseptic conditions, and the epiphyses were removed (Ocarino et al. 2010). The bone marrow was flushed with Dulbecco's modified Eagle's medium (DMEM; Gibco, Grand Island, N.Y., USA), and the released cells were suspended in DMEM, supplemented with $10 \%$ fetal bovine serum (Gibco) and antibiotics $(60 \mu \mathrm{g} / \mathrm{L}$ gentamicin, 25 $\mu \mathrm{g} / \mathrm{L}$ amphotericin $\mathrm{B}, 100 \mathrm{U} / \mathrm{mL}$ penicillin and $100 \mu \mathrm{g} / \mathrm{mL}$ streptomycin; Merck, Germany) and collected in a $75-\mathrm{cm}$ two-culture flask containing $10 \mathrm{~mL}$ of culture medium. The cells were grown at $37^{\circ} \mathrm{C} / 5 \% \mathrm{CO}_{2}$ for three days. The non-adherent cell population was removed and the adherent layer was washed once with fresh medium. The culture medium was changed two times in a week during the culturing.

\section{FACS Analysis}

Cells at the fourth passage were harvested with trypsin/EDTA, centrifuged at $1,400 \mathrm{rpm}$ for 10 $\mathrm{min}$ and re-suspended at $1 \times 10^{6}$ cells/well in phosphate-buffered saline (PBS). The cell aliquots were incubated with individual primary or control antibodies for $30 \mathrm{~min}$ at $4^{\circ} \mathrm{C}$ and were washed in PBS and incubated with fluorophore-conjugated secondary antibody for at $4{ }^{\circ} \mathrm{C}$ for $30 \mathrm{~min}$. The samples were analyzed using a FACScan cytometer (Becton Dickinson) and data were analyzed using the Cellquest software (Becton Dickinson). The following primary antibodies were used: anti-CD45, anti-CD90, anti-CD73 and anti-CD54 (BD Biosciences, San Jose, Calif., USA).

\section{Cells viability for blue trypan assay}

Immediately before the injection, the cells viability was analyzed. For trypan blue exclusion assay, the cells were exposed to trypan blue for $10 \mathrm{~min}$. The number of viable cells (by dye exclusion) was counted under the light microscope using a Neubauer camera and expressed as a percentage of total cells. 


\section{Venom}

The venom pool from the adult Rhinocerophis alternatus (Bothrops alternatus) snakes was dried in a vacuum desiccator at room temperature immediately after milking and then stored at $20^{\circ} \mathrm{C}$ until the moment of utilization.

\section{Animals Assays}

Seventy-five male Wistar rats with mean weight of $120 \mathrm{~g}$ were kept in cages $(40 \times 45 \times 45 \mathrm{~cm})$ and were maintained under the controlled light cycle $(12 / 12 \mathrm{~h})$ and temperature $\left(22 \pm 2^{\circ} \mathrm{C}\right)$ with free access to food and water for all the experiments. The study animals were distributed into three equal groups of 25 animals each, G1, G2 and G3. Rats of $\mathrm{G} 1$ and $\mathrm{G} 2$ received $120 \mu \mathrm{g}$ of $R$. alternatus venom diluted in $200 \mu \mathrm{L}$ of ultra pure water, while G3 received only $200 \mu \mathrm{L}$ of ultra pure water. Such doses were previously determined in a pilot experiment. In all the cases, administration occurred via intra muscular injection into right gastrocnemius muscle using a hypodermic syringe. After three days $(72 \mathrm{~h}), \mathrm{G} 1$ was treated with one injection of $5 \times 10^{6}$ MSC diluted in $200 \mu \mathrm{L}$ of PBS and G2 (positive control) and G3 were treated with $200 \mu \mathrm{L}$ of PBS (negative control). The time of treatment ( $72 \mathrm{~h}$ after venom inoculation) was chosen due the kinetics of $R$. alternatus ( $B$. alternatus) described by Mello et al. (2010).

Every three days after the treatments, blood was collected by cardiac puncture of five animals of each group on $3^{\text {rd }}(\mathrm{TI}), 6^{\text {th }}(\mathrm{TII}), 9^{\text {th }}(\mathrm{TIII}), 12^{\text {th }}$ (TIV) and $15^{\text {th }}$ (TV) day to perform the protein profile. All the animals were anesthetized by means of intramuscular injection in the contralateral limb of a mixture containing 10 $\mathrm{mg} / \mathrm{kg}$ of xylazine hydrochloride and $75 \mathrm{mg} / \mathrm{kg}$ of ketamine (Sigma Chemical Co. - USA).

Blood samples were stored in the flasks without anticoagulant. The total protein concentration was calculated by refratometer (Ningbo Utech International CO LTD) and the fractioned proteins (albumin, alfa, beta and gamma globulins) were evaluated by eletrophoresis in agarose gel (CELMGEL) (30 min) in TRIS buffer. The gels were stained for 5 minutes in $200 \mathrm{~mL}$ of Amido black and destained in acid acetic solution (7\%) until de gel background was completely clear. The concentration of protein fractions was determined by the use of computer-assisted software CELM SE- 250.

\section{Statistics}

The experiment followed a random design. Data were subjected to Lillifors, Kolmogorov-Smirnov and Shapiro-Wilk normality tests. The analysis of variance (ANOVA) was applied to variables that were normally distributed, the mean values of which were compared using the SNK test. Statistical analyses were carried out with the aid of SAS (Cary, NC, USA).

\section{RESULTS AND DISCUSSION}

The phenotypic characterization of the bone marrow MSC indicated that there was no CD45 expression in $96.94 \%$ of the cells. There was, however, expression of CD73, CD54 (intercellular adhesion molecule-1; ICAM-1) and CD90 in 93.99, 95.1 and $86.77 .0 \%$ of the cells, respectively.

Even under the anesthesia, after venom injection, pain was observed manifestating in all the G1 and $\mathrm{G} 2$ animals. There was muscle fasciculation in the right hind limb, which stayed flexed for about 20 h. Same demonstration was also observed by Dourado et al. (2008) in mice inoculated with B. neuwiedi venom for $12 \mathrm{~h}$. In the present study, the peak of hyperalgesia was observed after one hour after venom inoculation and clinical signs of pain gradually decreased and disappeared completely after $24 \mathrm{~h}$. The pharmacological basis of hyperalgesia and allodynia induced by the bothropic venom has been investigated and the involvement of various mediators, such as bradykinin and leucotrienes has shown a multifactorial mechanism in the onset of pain (Chacur et al. 2001). This effect can be potentialized by increased local pressure caused by edema. The envenomed animals (G1 and G2) showed moderate local edema, with no extension to the rest of the limb. In the cases of bothropic envenomation, local edema is commonly found and may worsen the hypovolemia condition. Bothropic envenomation causes rapid development of edema and inflammation at the bite site. The edema induced by these venoms is associated with the action of various substances such as hemorragins (that act directly on the endothelium of capillaries and small veins, increasing the permeability), cytotoxins (induce the release of histamine, PLA2, and arachidonic acid, which releases membrane phospholipids, 
leading to the synthesis of prostaglandins that, in turn, increases the capillary permeability), proteases (that break kininogen, releasing kinins and leading to the production of nitric oxide and prostaglandins), vasoactive peptides (inhibit the action of the angiotensin converting enzyme and boost the action of bradykinin); and components of the complement cascade (Gutiérrez et al. 2009). The injection of ultra pure water (control group) did not modify the pain threshold of the animals.

No macroscopic signs of hemorrhage, dermonecrosis and blistering were observed in all the animals, but envenomed animals stayed apathetic, hypoxemic and hypodipsic for about 24 $\mathrm{h}$, returning to normal activities after this period. As shown in Figure 1, there were differences in serum total protein values between G1 $(7.64+0.80$ $\mathrm{mg} / \mathrm{dL})$ and $\mathrm{G} 3(6.56 \pm 0.26 \mathrm{mg} / \mathrm{dL})$ in TI ( $3^{\text {rd }}$ day), probably due to an increase in $\alpha 1$-globulin fraction in G1, as shown in Figure 3. On the $12^{\text {th }}$ day (TIV), the G1 presented a significant reduction in total protein, when compared to others studied times (TI, TII, TIII and TV). A significant decrease in albumin values, as shown in Figure 2, could be responsible for this phenomenon.

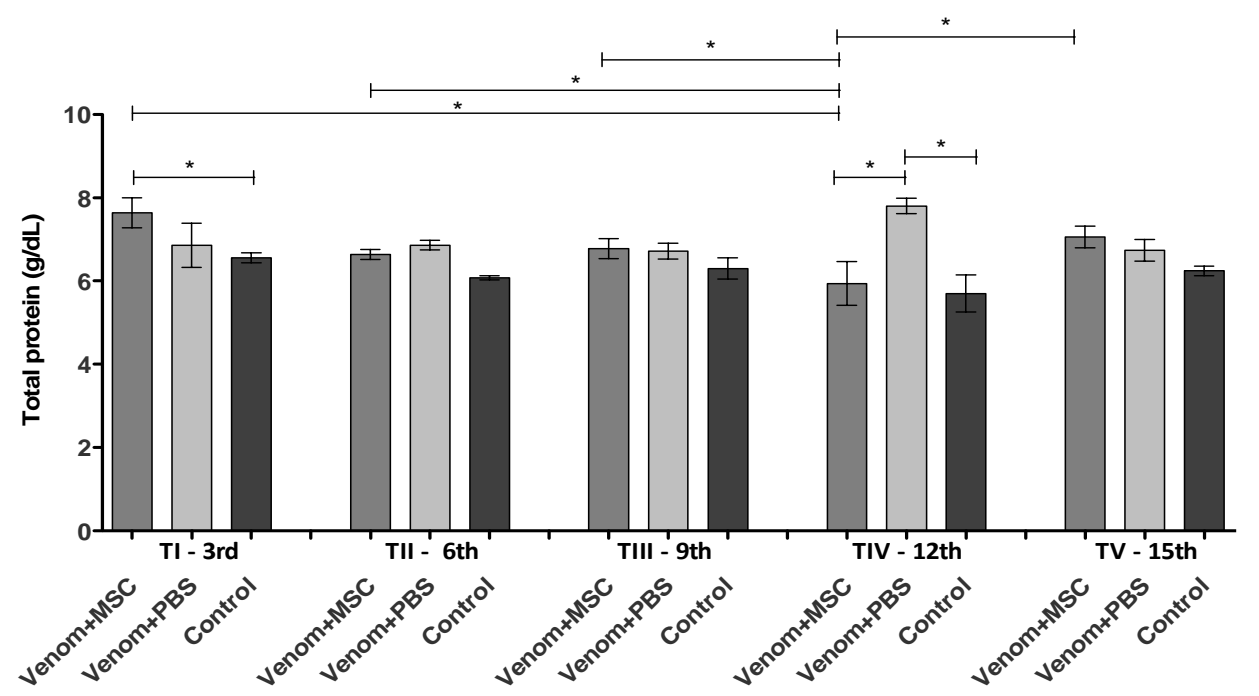

Figure 1 - Total protein (g/dl) serum levels (mean $\pm \mathrm{SD}$ ) in rats after Rhinocerophis alternatus venom inoculation treated with MSC (group 1) and PBS (group 2), and in rats after placebo inoculation (group 3) in different times. (P<0.05 according to SNK test).

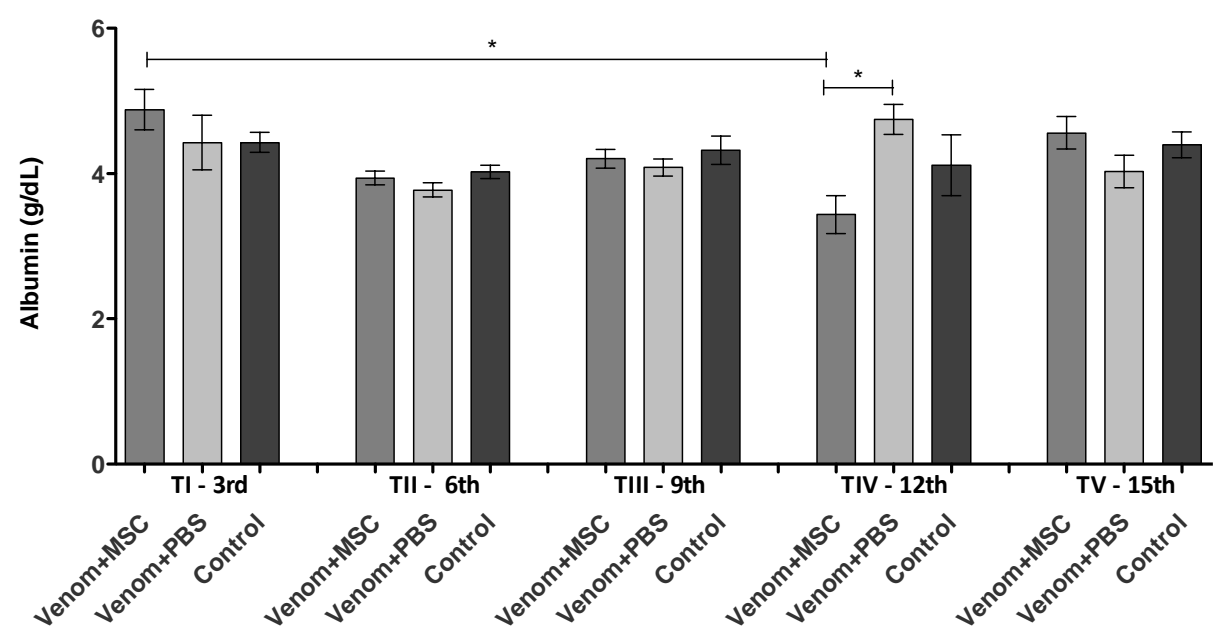

Figure 2 - Albumin $(\mathrm{mg} / \mathrm{dl})$ serum levels (mean $\pm \mathrm{SD}$ ) in rats after Rhinocerophis alternatus venom inoculation treated with MSC (group 1) and PBS (group 2), and in rats after placebo inoculation (group 3 ) in different times $(\mathrm{P}<0.05$ according to SNK test). 
There was no difference in the albumin levels between the groups during all the times, except $12^{\text {th }}$ day (TIV), when a decrease was observed $(\mathrm{P}<0.05)$ in G1. Albumin is a negative acute phase protein and its concentration gradually falls during the infectious and inflammatory diseases. The secretion of albumin is stimulated by a decrease in osmotic pressure but can also be affected by the pathophysiological changes such as during infectious or inflammatory disease when the secretion is reduced. This is caused by the proinflammatory cytokines such as interleukin (IL)-1, IL-6, and tumor necrosis factor- $\alpha$ (TNF). These cytokines are simultaneously responsible for the increased synthesis and secretion of the APP.
The results of $\alpha 1$-globulin showed statistical difference between groups only on $12^{\text {th }}$ day (Fig. $3)$, when there was an increase $(\mathrm{P}<0.05)$ of $\alpha 1$ globulin in the G2 (venom + PBS).

On $3^{\text {rd }}$ day (TI), the $\alpha 2$-globulin showed a statistically increase in the groups that received venom (G1 and G2) when compared to the control group (G3) (Fig 4). These values tended to decline over the time, and especially in G1 after 6 days (in TIII), there was a significant decrease in the $\alpha 2$ globulin fraction. The $\alpha 2$-globulin is considerate APP. Inside $\alpha 2$-globulin, there are two proteins, alfa-2-macroglobulin, and the haptoglobin, which is a moderate APP and responds to inflammatory and infectious disease.

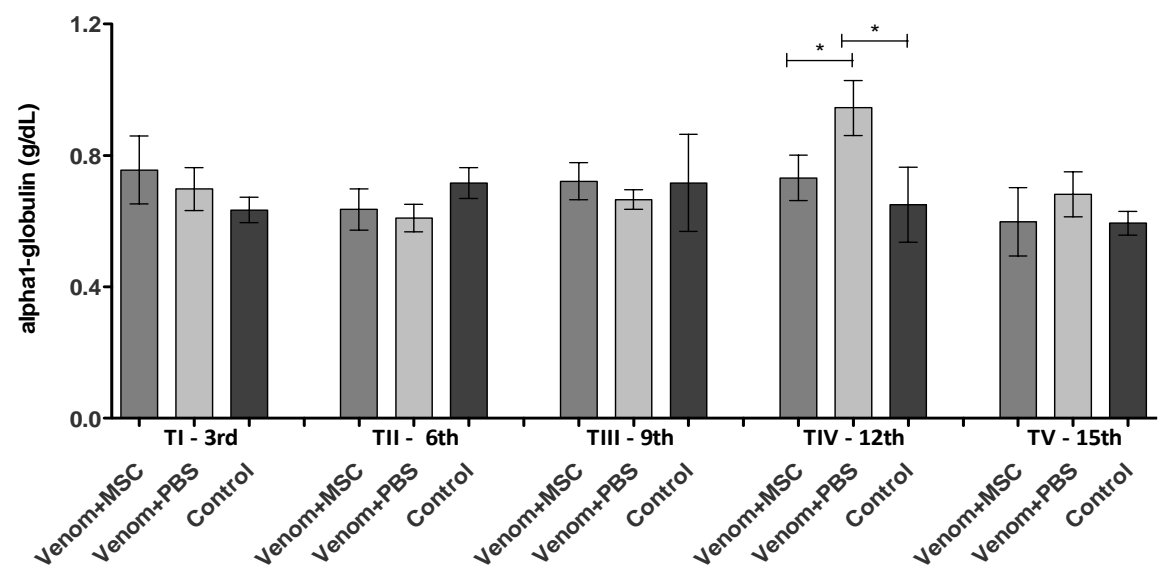

Figure 3 - $\alpha 1$-globulin $(\mathrm{g} / \mathrm{dl})$ serum levels (mean $\pm \mathrm{SD}$ ) in rats after Rhinocerophis alternatus venom inoculation treated with MSC (group 1) and PBS (group 2), and in rats after placebo inoculation (group 3 ) in different times ( $\mathrm{P}<0.05$ according to SNK test).

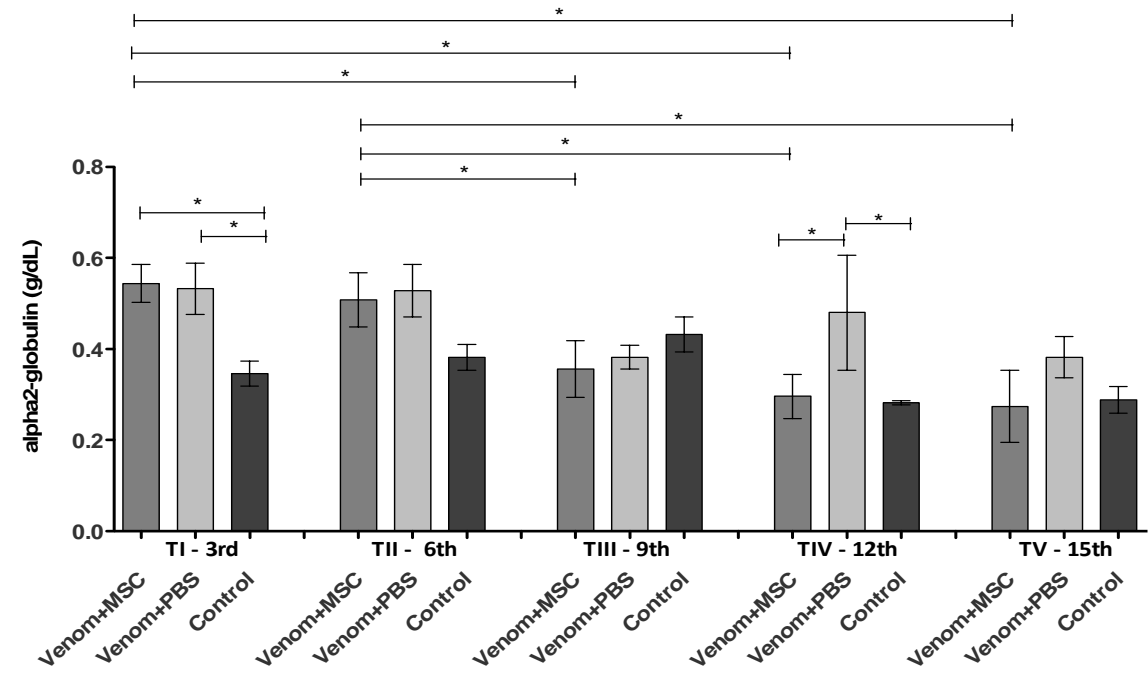

Figure 4 - $\alpha 2$-globulin $(\mathrm{g} / \mathrm{dl})$ serum levels (mean $\pm \mathrm{SD})$ in rats after Rhinocerophis alternatus venom inoculation treated with MSC (group 1) and PBS (group 2), and in rats after placebo inoculation (group 3 ) in different times $(\mathrm{P}<0.05$ according to SNK test). 
Evidently on $12^{\text {th }}$ day, the G2, group that received venom and was treated with PBS (placebo) showed an increase in $\alpha 1$ and $\alpha 2$ globulins. On the $3^{\text {rd }}, 6^{\text {th }}$ and $12^{\text {th }}$ days, the same group, G2, also showed an increase in beta globulins.

In the animals that received bothropic venom (G1 and $\mathrm{G} 2)$, the $\beta$-globulin was elevated until $12^{\text {th }}$ day (Fig. 5) when compared to the control (G3). These data agreed with those in literature describing an increase of the $\beta$-globulin in a latter phase of inflammatory process. The beta-globulins are $\beta$ lipoprotein and complement $\mathrm{C} 3$, which are located in the $\beta 1$ region, and transferrin and $\operatorname{IgM}$ which are located in the $\beta 2$ region. Transferrin and complement C3 participate in many immunological and inflammatory reactions. The activation of complement $\mathrm{C} 3$ has been described after snake venom envenomation. But it must be stressed that in the group that received the venom and was treated with MSC (G1), there was a significant decrease of beta globulins when compared with the group that received venom and was treated with placebo $(\mathrm{G} 2)$.

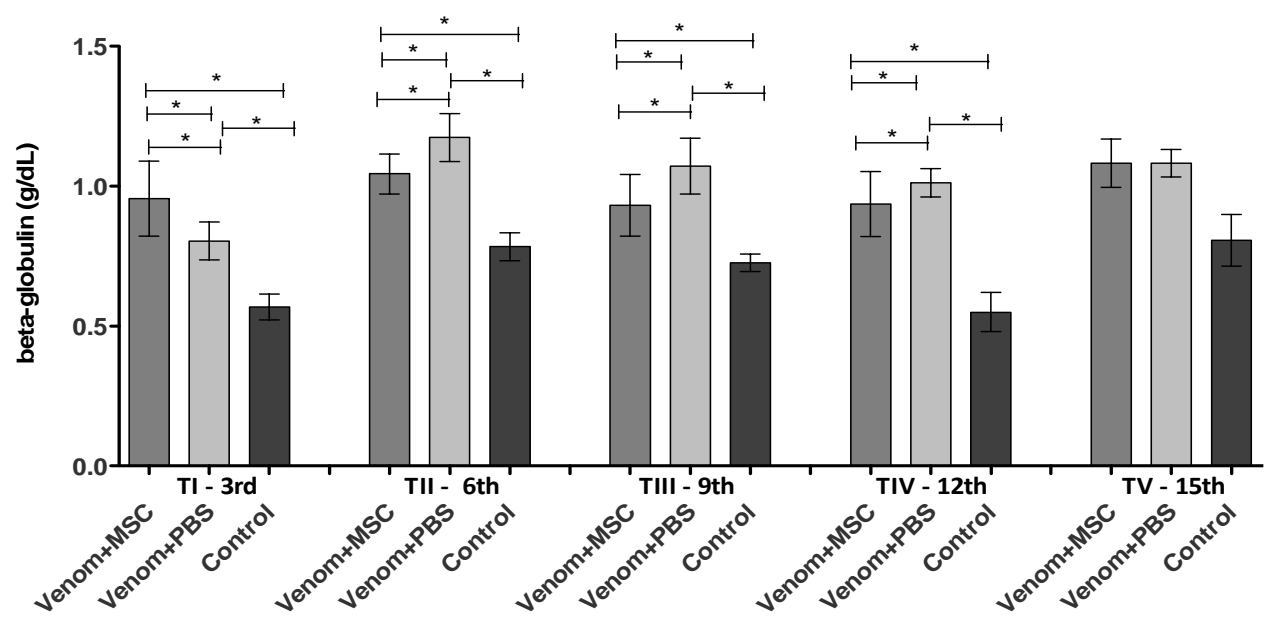

Figure 5 - $\beta$ globulin (g/dl) serum levels (mean $\pm \mathrm{SD}$ ) in rats after Rhinocerophis alternatus venom inoculation treated with MSC (group 1) and PBS (group 2), and in rats after placebo inoculation (group 3) in different times $(\mathrm{P}<0.05$ according to SNK test).

In order to understand this kind of envenomation and improve its therapeutic strategy, besides clinical and epidemiological studies, it is necessary to understand the role of inflammatory mediators such as nitric oxide (NO), cytokines and the complement system (Petricevich et al. 2000). Nitric oxide also participates in the pathogenesis of snake envenomations by two different mechanisms: it may lead to tissue damage due to its ability to generate peroxynitrite and hydroxyl radicals after interaction with superoxide ions, and, it may provoke hypotension by its vasodilator action (Radi et al. 1991; Hoog et al. 1992). The precise function of $\mathrm{NO}$ in snake envenomations has yet to be investigated, but it is probably important in the systemic effects caused by snake envenomations. The mechanism by which snake venoms induce the production of cytokines and
NO is unknown (Petricevich et al. 2000). It has been observed that the animals experimentally injected with Bothrops venoms showed leukocyte accumulation, which was dependent on eicosanoid release and chemotactic factors derived from the serum (Farsky et al. 1997). However, the latter effect is probably due to the complement activation (Dias-da-Silva et al. 1995.

According to Gutiérrez et al. (2009), local tissue damage is induced by Bothrops venom, neutrophils, cytokines, but nitric oxide does not contribute to a significant extent in the pathogenesis of myonecrosis in animal models. The scenario that emerges from these observations is one in which the local pathology is mostly caused by the direct action of venom PLA2s and metaloproteinases in the tissue. The prominent inflammatory reaction that ensues is likely to 
participate in the processes of tissue repair and regeneration. Therefore, the manipulation of the local inflammatory response has to be analyzed in the light of this hypothesis in order to promote its favorable aspects that contribute to tissue regeneration.

The last fraction normally viewed in electrophoresis is immunoglobulin ( $\operatorname{IgA}$ and $\operatorname{IgG}$ ), therefore, express mainly the IgG immunogamaglobulin, with a correlation with concentrations of immunochemistry. Thus, the statistical increase of $\gamma$-globulin in G1 and G2 compared to G3 (Fig. 6) was due to increase of $\mathrm{IgG}$, a common occurrence in bothropic envenomation.

Due to the increase of the globulins in the groups that received venom, a less significant albumin / globulin relationship was observed. However, this result was not observed on $9^{\text {th }}$ day (TIII), when the groups were statistically equal and differentiated on $12^{\text {th }}$ and $15^{\text {th }}$ day (Fig. 7).

This is first report on the activity of mesenchymal stem cells in the inflammation response caused by $R$. alternatus venom in vivo.

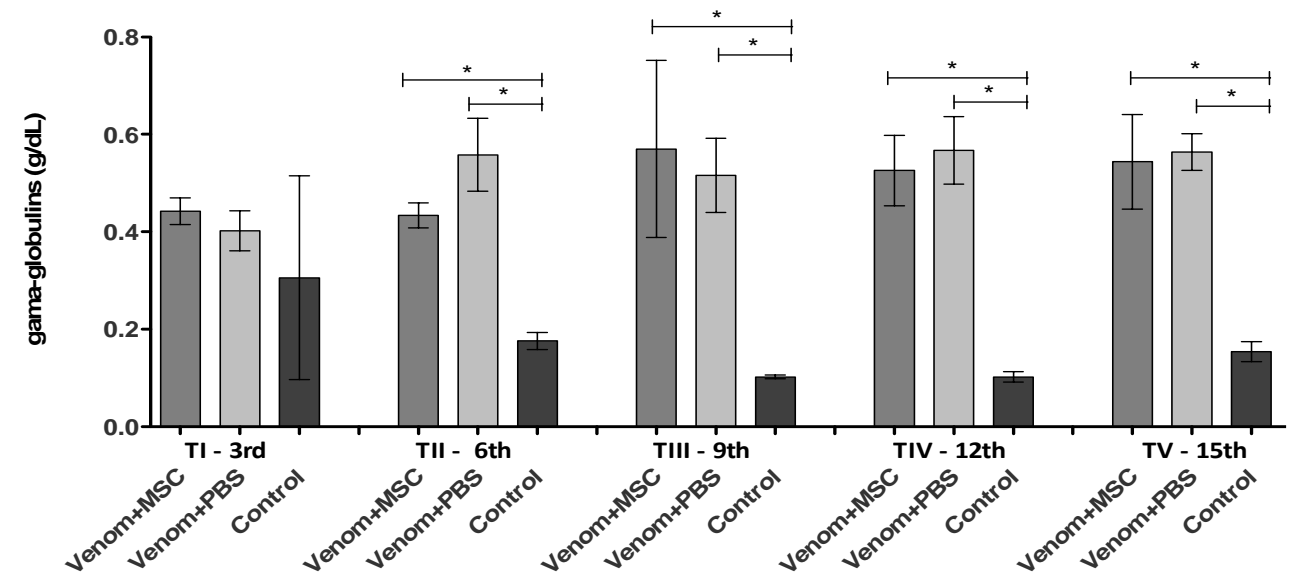

Figure 6 - $\gamma$ globulin $(\mathrm{g} / \mathrm{dl})$ serum levels (mean $\pm \mathrm{SD})$ in rats after Rhinocerophis alternatus venom inoculation treated with MSC (group 1) and PBS (group 2), and in rats after placebo inoculation (group 3) in different times ( $\mathrm{P}<0.05$ according to SNK test).

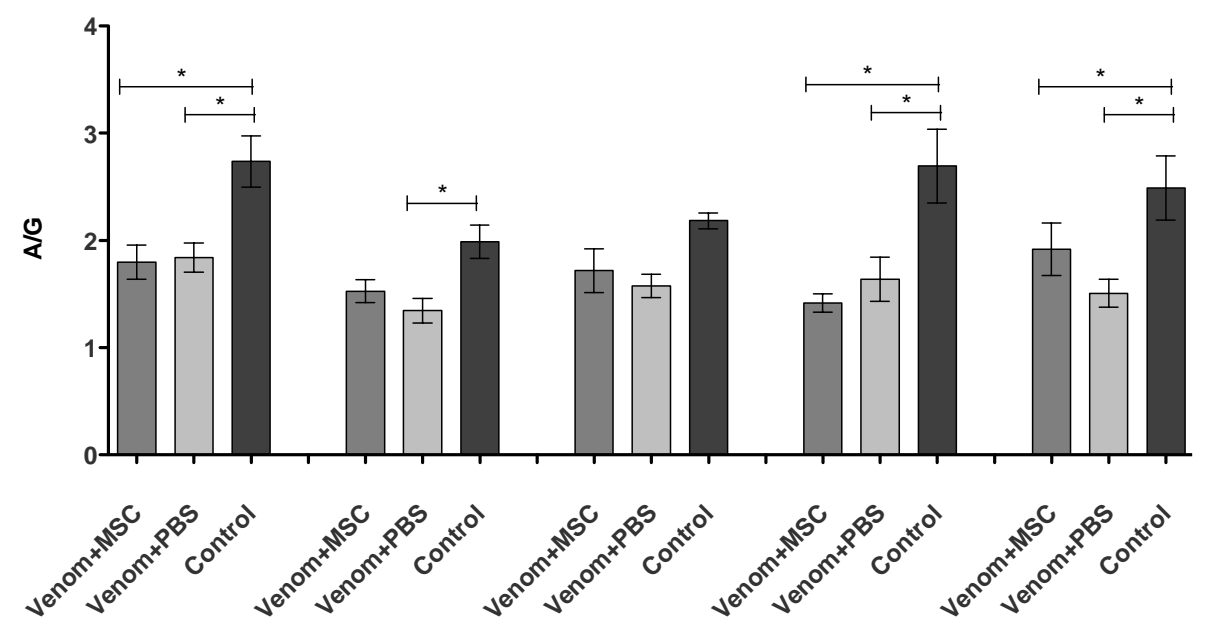

Figure 7 - Albumin/globulin (g/dl) serum levels (mean $\pm \mathrm{S}$ ) in rats after Rhinocerophis alternatus venom inoculation treated with MSC (group 1) and PBS (group 2), and in rats after placebo inoculation (group 3 ) in different times $(\mathrm{P}<0.05$ according to SNK test). 


\section{CONCLUSION}

These results showed that the MSC treatment after bothropic envenomation in the rats caused a decrease in $\alpha 2$-globulin and beta globulin fractions.

\section{ACKNOWLEDGEMENTS}

The authors acknowledge Prof. Dr. Angela Maria Quintão Lana for statistical advice and Prof. Dr. Rogéria Serakides for cells donation.

\section{REFERENCES}

Alonso L, Fuchs E. Stem cells of the skin epithelium. PNAS. 2003; 100(1): 11830-11835.

Battellino C, Piazza R, Da Silva AMM, Cury I, Farsky SHP. Assessment of efficacy of bothropic antivenom therapy on microcirculatory effects induced by Bothrops jararaca snake venom. Toxicon. 2003; 41(5): 583-593.

Bochner RS, Struchiner CJ. Epidemiologia dos acidentes ofídicos nos últimos 100 anos no Brasil: uma revisão. Cad Saúde Pública. 2003; 19(1): 7-16.

Chacur M, Picolo G, Gutiérrez JM, Teixeira CFP, Cury Y. Pharmacological modulation of hyperalgesia induced by Bothrops asper (terciopelo) snake venom. Toxicon. 2001; 39(8): 1173-1181.

Chiacchio SB, Martins GTB, Amorim RM, Gonçalves RC, Barraviera B, Ferreira Junior RS. Triple bothropic envenomation in horses caused by a single snake. J Venom Anim Toxins. 2011; 17(1): 111-117.

Da Silva NM, Arruda EZ, Murakami YL, Moraes RA, El-Kik CZ, Tomaz MA, Fernandes FF, et al. Evaluation of three Brazilian antivenom ability to antagonize myonecrosis and hemorrhage induced by Bothrops snake venoms in a mouse model. Toxicon. 2007; 50(2): 196-205.

Dias-Da-Silva W, Tambourgi DV, Campos ACMR, Magnoli F, Petricevich VL, Kipnis TL. Complement activation by animal venoms. Toxin Rev. 1995; 14(3): 375-400.

Dourado DM, Matias R, Almeida MF, De Paula KR, Vieira RP, Oliveira LVF, Carvalho PTC. The effects of low-level laser on muscle damage caused by Bothrops neuwiedi venom. J Venom Anim Toxins. 2008; 14(3): 423-434.

Farsky SH, Walber J, Costa-Cruz M, Cury Y, Teixeira CF. Leukocyte response induced by Bothrops jararaca crude venom: in vivo and in vitro studies. Toxicon. 1997; 35(2): 185-193.
Fuchs E. Skin stem cells: rising to the surface. J Cell Biol. 2008, 180(2): 273-284.

Gomillion CT, Burg KJL. Stem cell and adipose tissue engineering. Biomaterials. 2006; 27: 6052-6063.

Gutiérrez JM, Ownby CL. Skeletal muscle degeneration induced by venom phospholipases A2: insights into the mechanisms of local and systemic myotoxicity. Toxicon. 2003; 42(8): 915-931.

Gutiérrez JM, Rucavado A, Chaves F, Diaz C, Escalante T. Experimental pathology of local tissue damage induced by Bothrops asper snake venom. Toxicon. 2009; 54(7): 958-975.

Gutierrez JM, Escalante T, Rucavado A. Experimental pathophysiology of systemic alterations induced by Bothrops asper snake venom. Toxicon. 2009; 54(7): 976-87.

Hogg N, Darley-Usmar VM, Wilson MT, Moncada S. Production of hydroxyl radicals from the simultaneous generation of superoxide and nitric oxide. Biochem J. 1992; 281: 419-24.

Liu P, Dengue Z, Han S, Liu T, Wen N, Lu W, Geng X, Huang S, Jin Y. Tissue-engineered skin containing mesenchymal stem cell improves burn wounds. Artificial Organs. 2008; 32(12): 925-931.

Mello SM, Linardi A, Rennó AL, Tarsitano CAB, Pereira EM, Hyslop S. Renal kinetics of Bothrops alternatus (Urutu) snake venom in rats. Toxicon. 2010; 55(2): 470-480.

Metcalfe AD, Ferguson MWJ. Tissue engineering of replacement skin: the crossroads of biomaterials, wound healing, embryonic development, stem cell and regeneration. J R Soc Interface. 2007; 4(14): 413437.

Mors WB, Nascimento MC, Pereira BM, Pereira NA. Plant natural products active against snake bite - the molecular approach. Phytochesmitry. 2000; 55: 627 642.

Ocarino NM, Boeloni JN, Jorgetti V, Gomes DA, Goes $\mathrm{AM}$, Serakides R. Intra-bone marrow injection of

mesenchymal stem cells improves the femur bone mass of osteoporotic female rats. Connective Tissue Res. 2010; 51(6): 426-433.

Petricevich VL, Teixeira CFP, Tambourghi DV, Gutiérrez JM. Increments in serum cytokine and nitric oxide levels in mice injected with Bothrops asper and Bothrops jararaca snake venom. Toxicon. 2000; 38(9): 1253-1266.

Quesada L, Sevcik C, Lomonte B, Rojas E, Gutiérrez JM. Pharmacokinetics of whole IgG equine antivenom: comparison between normal and envenomed rabbits. Toxicon. 2006; 48(3): 255-263.

Radi RB, Beckman JS, Bush KM, Freeman BA. Peroxynitrite oxidation of sulphydryls. The cytotoxic potential of superoxide and nitric oxide. J Biol Chem. 1991; 266: 4244-4250. 